\title{
Reflexões sobre desenvolvimento de carreira de violonistas sobre atividades musicais
}

\author{
Marilda Aparecida Dantas ${ }^{1}$ \\ Universidade Estadual de Campinas, Campinas/SP, Brasil \\ Roberta Gurgel Azzi \\ TSC - Centro de Estudos e Pesquisas, Bragança Paulista/SP \\ Cristina Tourinho \\ Departamento de Música/Universidade Federal da Bahia - UFBA
}

\section{Resumo}

Foi objetivo deste trabalho verificar o conhecimento e as percepções de autoeficácia ocupacional de estudantes e profissionais violonistas e comparar os resultados quanto a variáveis pessoais. A Teoria Social Cognitiva de Carreira norteou esta investigação. Foram 83 participantes violonistas de diversas regiões do Brasil que responderam a Escala de Autoeficácia Ocupacional de modo online. Os resultados indicaram que há diversas ocupações desconhecidas para os participantes e que suas percepções de autoeficácia tendem para as ocupações conhecidas. Foram identificadas diferenças significativas somente na comparação do grupo que finalizou o curso entre $2000 \mathrm{e}$ 2009. Houve correlações significativas positivas entre as variáveis estudadas. Os dados indicaram a necessidade de intervenções estruturadas para a formação do profissional e desenvolvimento de carreira.

Palavras-chave: trabalho, música, autoeficácia

\section{Abstract: Reflections on guitarists career development about musical activities}

The aim of this study was to verify the knowledge and perceptions of occupational self - efficacy of students and professional guitarists and compare the results regarding personal variables. The Cognitive Social Career Theory guided this research. There were 83 guitarist participants from different regions of Brazil who answered the Occupational Self-Efficacy Scale online. The results indicated that there are several occupations unknown to the participants and that their perceptions of self-efficacy tend towards known occupations. Significant differences were identified only in the comparison of the group that finished the course between 2000 and 2009. There were significant positive correlations between the studied variables. The data indicated the need of structured interventions for professional training and career development.

Keywords: work, music, self-efficacy.

Resumen: Reflexiones sobre el desarrollo de carrera de guitarristas con relación a las actividades musicales Fue objetivo de este trabajo verificar el conocimiento y las percepciones de autoeficacia ocupacional de estudiantes y profesionales guitarristas y comparar los resultados de variables personales. La Teoría Social Cognitiva de Carrera orientó esta investigación. Fueron 83 participantes guitarristas de diversas regiones de Brasil que respondieron la Escala de Autoeficacia Ocupacional de modo online. Los resultados indicaron que existen diversas ocupaciones desconocidas por los participantes y que sus percepciones de autoeficacia tienden a ocupaciones conocidas. Se identificaron diferencias significativas sólo en la comparación del grupo que finalizó el curso entre 2000 y 2009 . Hubo correlaciones significativas positivas entre las variables estudiadas. Los datos indicaron la necesidad de intervenciones estructuradas para la formación profesional y el desarrollo de carrera.

Palabras clave: trabajo, música, autoeficacia.

1 Endereço para correspondência: Rua Joaquim Pinto de Andrade, 315, apto 34 - Jardim Botânico, Jaguariúna/SP

E-mail: marildapsi@uol.com.br 


\section{Introdução}

O objetivo desta investigação foi verificar o conhecimento e as percepções de autoeficácia ocupacional em atividades musicais junto a estudantes de graduação em música e músicos profissionais. Embasada na Teoria Social Cognitiva de Carreira (TSCC), a proposta teórica desta pesquisa busca pesquisar, compreender, analisar, discutir e intervir no campo de desenvolvimento de carreira, com ênfase no papel dos pensamentos autorreferentes na motivação e no comportamento humano, no desenvolvimento de interesses e nas escolhas do campo ocupacional e acadêmico (Lent, Brown, \& Hacket, 1994).

As crenças de autoeficácia configuram o escopo da TSCC e são compreendidas como "crenças sobre as capacidades para organizar e executar o curso de uma determinada ação para produzir realizações" (Bandura, 1997, p.3). Elas podem afetar a motivação, o bem-estar e as realizações e sua importância advém do fato de que, se a pessoa pouco acredita que pode produzir efeitos desejáveis sobre suas ações, ela tende a ter pouco incentivo para agir ou para perseverar diante das dificuldades (Bandura, 1997; 2008). As crenças de eficácia desempenham um papel de mediação nas realizações e de preditora motivacional do comportamento, sendo que alterações nas percepções de crenças de eficácia impactarão sobre as realizações. Embora sejam funcionalmente ligadas as ações, há uma série de fatores que podem afetar as suas relações; assim a crença de autoeficácia não é uma capacidade fixa, um número de habilidades ou conhecimento que se tem ou não, mas sim aquilo que o indivíduo acredita que pode fazer com o que tem em uma variedade de circunstâncias (Bandura, 1997)

É reconhecido que as crenças exercem um papel central na cognição, na motivação e no comportamento humano, de modo que possibilitam às pessoas terem algum grau de controle sobre seus pensamentos, sentimentos e ações, sendo fundamentais para o exercício de controle e realização pessoal, cultural e social (Pajares \& \& Olaz, 2008). A inserção do construto das crenças de autoeficácia na configuração da Teoria Social Cognitiva de Carreira data a década de 1980 e advém do domínio da matemática. Isso teve início quando a professora norte-americana Nancy Betz, uma das pioneiras da TSCC, notou a pouca representatividade das mulheres em carreiras do campo da matemática e ciências e quando se estudou as barreiras encontradas por elas na busca de carreiras dessa área. Os primeiros estudos dessa pesquisadora revelaram que as percepções de crenças de autoeficácia enfraquecidas das mulheres para atividades tradicionalmente masculinas (naquela cultura e época, pelo menos) eram possíveis fontes da baixa inserção delas nessas atividades. Ou seja, estas mulheres pesquisadas pouco acreditavam que poderiam assumir atividades que até então eram exercidas na sua maioria por homens. O baixo crédito que elas mesmas davam a si para exercer atividades em campos da matemática e ciências, ocupados tradicionalmente por homens, poderia ter um impacto nos esforços e interesses delas para ingressar na área. Assim, pela ótica das crenças de autoeficácia, quanto menos se acredita em ser capaz de realizar alguma atividade, menos se engajará para realizá -la (Betz, 2004).

$\mathrm{Na}$ perspectiva de desenvolvimento de carreira, assim como as crenças de autoeficácia relacionadas à matemática são consideradas como preditoras do comportamento na escolha acadêmica e profissional, outros domínios de crenças de autoeficácia, relacionados diretamente às ocupações também o são. Ainda que inúmeras investigações apresentam diferentes domínios de conteúdo quanto às crenças de autoeficácia, os resultados confirmam o modelo teórico explicativo de interesses e escolhas nas quais se observou o impacto das percepções de autoeficácia na definição de interesses (Betz \& Hackett, 1981; Betz, 2004; Dantas \& Azzi, 2015; Masotti \& Noronha, 2015) e escolhas acadêmicas e profissionais (Coimbra \& Fontaine; 2010; Lent, Brown, Nota, \& Soresi, 2003a; Lent, Paixão, Silva, \& Leitão, 2010). Resultados de estudos sobre autoeficácia em domínios relacionados ao conteúdo técnico/científico e matemático apontaram que os estudantes que se percebiam mais autoeficazes apresentaram desempenho acadêmico mais elevado e maior persistência ao longo do curso (Lent, Brown, \& Larkin, 1984; 1987). Além disso, as crenças de autoeficácia percebidas foram preditoras comportamentais de realização acadêmica, persistência ao longo do curso, interesses ocupacionais (Lent et al., 1987; 2003b) e maior amplitude de opções de carreira (Lent et al., 1987).

As pesquisas sobre autoeficácia em música no Brasil vem se expandindo, principalmente em trabalhos apresentados no SIMCAM (Simpósio Internacional de Cognição e Artes Musicais), que reúne anualmente em diferentes cidades do Brasil pesquisadores interessados neste tema. Os trabalhos apresentados no $12^{\circ}$ SIMCAM, realizado em Porto Alegre, em maio de 2016, versaram sobre as percepções de professores na área musical em educação infantil (Ropke, 2016; Werner, 2016), ensino médio (Kruger, 2016), ensino de música no contexto da escola pública brasileira (Cereser, Oliveira \& Hentschke, 2016, Brazil, 2017), e na área ocupacional a percepção de autoeficácia para atuação profissional de violonistas (Tourinho \& Azzi, 2016).Outro estudo sobre a autoeficácia no domínio ocupacional foi desenvolvido por Dantas e Azzi (2015), no qual estudantes do ensino médio responderam o quanto se sentiam capazes de completar com sucesso a formação necessária para atuar na área de uma lista de 52 ocupações, dentre elas a de "Músico". Dos 198 participantes 36,55\% responderam que "Sim" percebiam-se capazes e 63,45 "Não". De acordo com as autoras, não foi esperado que a totalidade de participantes se percebessem capazes; de algum modo as percepções desses estudantes 
refletiram nos interesses deles para a referida ocupação. Ainda assim, é possível verificar que as percepções de autoeficácia podem ser enfraquecidas ou fortalecidas ao longo do tempo, de modo planejado ou não, por exemplo, por meio de intervenções (Dantas, 2015; Tourinho, Azzi, \& Dantas, 2016).

O que se observa é que as percepções de crenças de autoeficácia não atuam de modo isolado; há um conjunto de processos cognitivos envolvidos no processo de realização das pessoas. Os elementos autorreferentes derivados dos trabalhos de Betz e Hackett (1981) e de outros foram utilizados como arcabouço para que Lent et al. (1994), a partir de análise de estudos empíricos, formulassem modelos teóricos explicativos do desenvolvimento de carreira. O primeiro modelo teórico formulado é o de interesses e envolve a formação e elaboração de interesses. O segundo modelo teórico, o de escolhas, envolve a seleção de escolhas acadêmicas e de carreira. E o terceiro, o de desempenho, que abrange o desempenho e persistência na busca educacional e ocupacional. Nos modelos teóricos estão envolvidos processos psicológicos que implicam as crenças de autoeficácia, as expectativas de resultados e dos objetivos, sendo recorrentes, interrelacionados, e desenvolvendo-se ao longo da vida.

O mercado de trabalho na área musical no Brasil cada vez mais apresenta características ecléticas para a atuação, o que pode ser considerado um fator relevante para o desenvolvimento de carreira, tanto para quem almeja se inserir nesta área, quanto para quem já atua nela. Isso porque ao considerar o modelo teórico da TSCC, o modo como as informações são percebidas pelos indivíduos podem impactar como fatores de apoio ou não. Segundo Salazar (2010, p.21) a música está presente em todos os grupos sociais, independente de faixas etárias e com distintas finalidades das tradicionalmente pensadas. O campo de atuação e oportunidades para músicos foi ampliado visivelmente nas últimas três décadas, disputando o graduado em música com o não graduado. Salazar (2010) lista quarenta diferentes formas de atuação profissional para músicos, que passam por trabalhos técnicos, artísticos, comerciais e instrucionais, o que ele chama de oportunidades de "negócios" em música.

Embora haja uma vasta lista de atuação proposta por Salazar (2010), por outro lado nota-se que os estudos acadêmicos brasileiros estão estruturados em duas vertentes principais: a atuação do professor e sua formação, e a aprendizagem do violonista em formação; poucos tratam da inserção do músico profissional no mercado de trabalho. Há vários desafios para o profissional da área de música. Taubkin (2011) analisa o que considera "viver de música" em entrevista com dezoito artistas brasileiros, músicos populares, luthiers, professores universitários, maestros e arranjadores. $\mathrm{O}$ autor considera músicos os que "vivem de música", entendendo que são pessoas que tiram do seu fazer musical os ganhos para sua subsistência. Transcrevemos abaixo o trecho de uma das entrevistas:

\begin{abstract}
Quando eu estou tocando, é tudo isso junto.... E eu consegui ter a minha casa, tenho minha familia. Eu diria para você que eu acho que é um trabalho como outro qualquer. Você tem que procurar fazer o seu trabalho, procurar ter uma rotina e fazer bem o seu trabalho. Passo, sim, alguns apertos de vez em quando .... Não tenho tino comercial, essa facilidade para lidar com dinheiro .... se nesse mês entrou mais no mês que vem pode entrar menos.... eu não trocaria de maneira nenhuma o que eu faço hoje por nada. Por mais aperto que eu passe .... trabalho nunca vai faltar .... (Braz da Viola, entrevista a Taubkin, 2011, p. 21-2)
\end{abstract}

O próprio autor analisa que “... algo totalmente arriscado, imponderável e até mesmo perigoso faz com que muitos dos que se dedicam a ela terminem abdicando de seus aspectos mais enriquecedores e significativos" (Taubkin, 2011, p.7-8). Entendem-se estes receios indo de encontro à idealização de uma profissão que traga muita realização pessoal, prazer, trocas criativas, mas que necessita, como em várias outras, dedicação e estudo. $O$ violão faz ou fez parte do universo de oito dos dezoito entrevistados, sendo que oito (não os mesmos) tiveram formação superior em música. A relação benefício financeiro e criação musical é bem expressa na p. 314: "O dinheiro me possibilita exercer a minha liberdade, então a minha relação com dinheiro é igual à que eu tenho com violão, com piano. Não é igual a relação com gente, porque gente é melhor do que música e do que dinheiro...".

Ainda utilizando Taubkin, o instrumento violão faz ou fez parte da vida de oito dos dezoito músicos entrevistados. Um número bem expressivo, se considerarmos que entre os que não tiveram sua iniciação instrumental com violão, um é violeiro e luthier, dois são compositores e produtores musicais, dois são flautistas, três são percussionistas e dois tocam teclados. Portanto, o violão representa um instrumento mais que presente quando se pensa em aprender um instrumento musical. Pode-se conjeturar que esse fato se dá não só pela popularidade do instrumento como também pelo baixo custo dos modelos mais simples. Assim, vale apontar que o conhecimento sobre a atuação profissional do músico, mundo do trabalho, apoios e barreiras percebidos podem contribuir para o desenvolvimento de interesses na área, bem como a aproximação ou não dela.

De acordo com o exposto, os objetivos específicos desta investigação com estudantes e profissionais de música violonistas foram de: 1) verificar as ocupações relacionadas à área de música mais conhecidas pelos participantes; 2) verificar as percepções dos participantes 
sobre as crenças de autoeficácia ocupacional em atividades musicais, comparando os grupos quanto ao sexo, idade, ano de ingresso e se exerce atividade remunerada; e 3) correlacionar as variáveis de totalidade de ocupações conhecidas, a totalidade de ocupações que se percebe capaz e o grau de certeza que se percebe capaz para atuar com sucesso na ocupação.

\section{Método}

\section{Participantes}

Foram participantes 83 sujeitos entre estudantes de graduação em música e profissionais de música, oriundos de 31 instituições de ensino superior do país, sendo $6(7,23 \%)$ do sexo feminino e $77(92,77 \%)$ do sexo masculino. A idade mínima foi de 18 anos e a máxima de 50 anos. $\mathrm{O}$ ano de ingresso no curso de graduação variou entre 1964 e 2014. Ao serem questionados sobre se conheciam as disciplinas do curso e sabiam o que elas ofereciam como conteúdo $5(6,06 \%)$ responderam que "Não", 44 (53,01\%) que "Parcialmente" e 34 (40,96\%) que "Sim". Dos 83 participantes $42(50,6 \%)$ responderam que realizam alguma atividade musical não remunerada.

\section{Instrumentos}

Para a coleta de dados foi utilizado um questionário de caracterização e a Escala de Autoeficácia Ocupacional, adaptada de Coimbra (2000) e Salazar (2010). O questionário de caracterização foi composto por questões relacionadas a aspectos pessoais, de formação e profissionais. A Escala de Autoeficácia Ocupacional foi adaptada para o contexto brasileiro e verificada evidências de validade (Dantas, Azzi, \& Noronha, no prelo). Para a presente investigação foi realizada uma nova adaptação da escala conforme Salazar (2010, p. 24) na qual se utilizou 48 atividades ocupacionais relacionadas à atuação profissional em música, compondo a escala com 48 itens. Assim, os participantes responderam à pergunta "acha que seria capaz de atuar com sucesso nesta atividade?" para cada item que correspondeu a uma atividade na área musical. Caso respondesse "Sim", foi solicitado que indicasse qual o grau de certeza sobre sua percepção, de acordo com uma escala Likert que variou de 1 a 4 , sendo 1 pouca e 4 toda a certeza. Os dados da escala foram submetidos à análise de consistência interna (alfa de Cronbach) obtendo coeficiente de 0,83 para a subscala "Se seria capaz" e 0,89 para "Grau de Certeza", sendo considerados valores satisfatórios (Nunes \& Primi, 2010).

\section{Procedimentos}

Este trabalho faz parte de um projeto maior cuja aprovação do Comitê de Ética em pesquisa da
Faculdade de Ciências Médica da Unicamp foi de número 10797213.7.0000.5404. Os respondentes foram contatados a partir dos professores de violão atuantes em cursos de Bacharelado em Violão e também diretamente, por e-mail, de acordo com uma lista construída a partir de sites e referências pessoais de uma das pesquisadoras desta investigação. A participação na pesquisa foi voluntária e consistiu em responder à Escala de Autoeficácia Ocupacional de modo online pela plataforma do software Survey Monkey ${ }^{2}$, bem como o aceite de participação na pesquisa por meio do Termo de Consentimento Livre e Esclarecido. Não houve tempo limite para responder ao questionário, estimou-se que 25 minutos foi o tempo médio para concluí-lo.

Os dados foram transferidos da plataforma Survey Monkey para uma planilha, analisados por meio do programa estatístico SAS e submetidos à análise descritiva e inferencial. Foi aplicado o teste de Shapiro-Wilk para a verificação da distribuição dos dados nos quais se encontrou a ausência de distribuição Normal, o que definiu as escolhas das provas estatísticas utilizadas que serão apresentadas nos resultados.

\section{Resultados}

Os resultados serão apresentados inicialmente pelas atividades ocupacionais em música mais e menos conhecidas pelos participantes (Tabela 1), suas percepções de autoeficácia ocupacional em música (Tabela 2), análises comparativas entre grupos formados pelas características pessoais (sexo e idade), de formação (ano de ingresso e finalização da graduação) e profissional (se exerce atividade remunerada) dos participantes (Tabelas 3 e 4), e por fim, a análise de correlação entre as percepções de autoeficácia ocupacional, atividades conhecidas e grau de certeza (Tabela 5).

$\mathrm{Na}$ Tabela 1 são apresentados os dados sobre o conhecimento dos participantes sobre atividades ocupacionais em música, sendo que as menos conhecidas estão em ordem crescente e as mais conhecidas em ordem decrescente. Das atividades mais conhecidas notouse que "Concertista" e "Professor Particular" eram de conhecimento de todos os participantes. Posteriormente, "Instrumentista/Intérprete", "Arranjador" e "Música de câmara" eram de conhecimento de quase todos os participantes $(98,70 \%)$.

No outro extremo da tabela é possível identificar as ocupações em atividades musicais menos conhecidas pelos participantes, sendo que pelo menos 7 atividades foram desconhecidas para mais de $25 \%$ dos participantes e 57,50\% deles não conheciam a atividade de "Agenciamento". Os dados indicaram que há mais ocupações conhecidas pelos participantes do que desconhecidas,

\footnotetext{
http://pt.surveymonkey.com/
} 
Tabela 1

Análises descritivas das ocupações de atividades musicais mais conhecidas pelos participantes

\begin{tabular}{|c|c|c|c|c|}
\hline \multirow{3}{*}{ Ocupação } & \multicolumn{4}{|c|}{ Conhece a ocupação? } \\
\hline & \multicolumn{2}{|c|}{ Não } & \multicolumn{2}{|c|}{ Sim } \\
\hline & $F$ & $\%$ & $f$ & $\%$ \\
\hline 28- Concertista (recitais solo) & - & - & 77 & 100 \\
\hline 30- Professor particular & - & - & 76 & 100 \\
\hline 20- Instrumentista ou intérprete (tocando, cantando, gravando p/ terceiros) & 1 & 1,30 & 76 & $\mathbf{9 8 , 7 0}$ \\
\hline 22- Arranjador & 1 & 1,30 & 76 & $\mathbf{9 8 , 7 0}$ \\
\hline 29- Música de câmara & 1 & 1,30 & 76 & $\mathbf{9 8 , 7 0}$ \\
\hline 1-Banda/conjunto autoral & 2 & 2,41 & 81 & 97,89 \\
\hline 31- Professor de escola pública regular & 2 & 2,63 & 74 & 97,37 \\
\hline 32- Professor de escola particular regular & 2 & 2,63 & 74 & 97,37 \\
\hline 35- Pesquisador & 2 & 2,63 & 74 & 97,37 \\
\hline 19- Composição (autor) & 3 & 3,90 & 74 & 96,10 \\
\hline 27- Solista de orquestra & 3 & 3,95 & 73 & 96,05 \\
\hline 33- Professor universitário & 3 & 3,95 & 73 & 96,05 \\
\hline 24- Trilha sonora (publicidade, jogos, teatro, cinema, moda) & 4 & 5,19 & 73 & 94,81 \\
\hline 2- Banda/conjunto tributo ou cover & 5 & 6,02 & 78 & 93,98 \\
\hline 3- Banda/conjunto/orquestra de baile & 5 & 6,02 & 78 & 93,98 \\
\hline 23- Maestro & 5 & 6,67 & 70 & 93,33 \\
\hline 37- Estúdio de gravação & 5 & 6,58 & 71 & 93,42 \\
\hline 42- Organização de eventos (festivais, concursos, prêmios, shows) & 5 & 6,48 & 72 & 93,51 \\
\hline 12- Casa de show, teatro, boate, bar (música ao vivo) & 6 & 7,59 & 73 & 92,41 \\
\hline 21- Cantor independente (voz e violão, voz e teclado) & 6 & 7,89 & 70 & 92,11 \\
\hline 34- Professor em projetos sociais & 6 & 7,79 & 71 & 92,21 \\
\hline 36- Estúdio de ensaios & 6 & 7,89 & 70 & 92,11 \\
\hline 17- Comércio de instrumentos, equipamentos e acessórios & 7 & 9,09 & 70 & 90,91 \\
\hline 43- Marketing cultural (elaboração e captação de projetos musicais) & 7 & 9,09 & 70 & 90,91 \\
\hline 26- Sinfônica (emprego público) & 8 & 10,53 & 68 & 89,47 \\
\hline 4- Sonorização para eventos & 9 & 11,11 & 72 & 88,89 \\
\hline 16- Comércio de CD, DVD e afins & 9 & 11,69 & 68 & 88,31 \\
\hline 18- Fabricação e reparo de instrumentos, equip. e acessórios & 10 & 12,99 & 67 & 87,01 \\
\hline 25- DJ (rádio, show, festa, boate) & 10 & 13,16 & 66 & 86,84 \\
\hline 39- Mixagem & 10 & 13,14 & 66 & 86,84 \\
\hline 44- Design (capas e encartes de CD e DVD musicais, material gráfico) & 10 & 12,99 & 67 & 87,01 \\
\hline 6- Empresariamento artístico (management) & 11 & 13,58 & 70 & 86,42 \\
\hline 8- Produção executiva (show ou CD,DVD) & 11 & 13,92 & 68 & 86,08 \\
\hline 13- Produção fonográfica (gravadora) & 11 & 14,10 & 67 & 85,90 \\
\hline 14- Edição musical (editora) & 11 & 14,47 & 65 & 85,53 \\
\hline 47- Produtora de vídeo (clipes, documentários, DVDs) & 11 & 14,29 & 66 & 85,71 \\
\hline 10- Técnica (som, luz, palco) & 12 & 15,19 & 67 & 84,81 \\
\hline 11- Direção artística (CD. DVD ou show) & 12 & 15,38 & 66 & 84,62 \\
\hline
\end{tabular}

(Continua) 
Tabela 1

Análises descritivas das ocupações de atividades musicais mais conhecidas pelos participantes (Continuação)

\begin{tabular}{|c|c|c|c|c|}
\hline \multirow{3}{*}{ Ocupação } & \multicolumn{4}{|c|}{ Conhece a ocupação? } \\
\hline & \multicolumn{2}{|c|}{ Não } & \multicolumn{2}{|c|}{ Sim } \\
\hline & $F$ & $\%$ & $f$ & $\%$ \\
\hline 40- Masterização & 13 & 16,88 & 64 & 83,12 \\
\hline 46- Assessoria de imprensa (especializada em música) & 17 & 22,08 & 60 & 77,92 \\
\hline 45- Web (programação ou design para o setor) & 19 & 24,68 & 58 & 75,32 \\
\hline 5- Montagem de estrutura $p$. eventos musicais & 22 & 27,50 & 58 & 72,50 \\
\hline 9- Produção de tournê (tour management) & 23 & 29,87 & 54 & 70,13 \\
\hline 41- Replicação de mídia (vinil, CD, DVD) & 28 & 36,36 & 49 & 63,64 \\
\hline 15- Distribuição de discos (distribuidora) & 29 & 37,66 & 48 & 62,34 \\
\hline 38- Estúdio móvel & 29 & 38,16 & 47 & 61,84 \\
\hline 48- Tecnologia da Informação (produtos para o setor) & 36 & 46,75 & 41 & 53,25 \\
\hline 7- Agenciamento (booking) & 46 & $\mathbf{5 7 , 5 0}$ & 34 & 42,50 \\
\hline
\end{tabular}

embora não seja de conhecimento de todos eles a amplitude de possibilidades de atuação na área musical.

Os dados da Tabela 2 apresentam as médias (em ordem decrescente) das percepções de autoeficácia ocupacional dos participantes. As ocupações com médias mais elevadas foram: professor particular $(\mathrm{m}=3,72-$ $\mathrm{dp}=0,58)$, professor universitário $(\mathrm{m}=3,62-\mathrm{dp}=0,72)$, instrumentista ou intérprete $(\mathrm{m}=3,56-\mathrm{dp}=0,72)$, música de câmara $(\mathrm{m}=3,55-\mathrm{dp}=0,74)$ e concertista $(\mathrm{m}=3,39$ $-\mathrm{dp}=0,88)$. Em comparação com a Tabela 1 é possível identificar que estas cinco atividades ocupacionais que apresentaram maiores médias na percepção de autoeficácia também estão classificadas como as mais conhecidas pelos participantes.

Das atividades ocupacionais com as menores médias de autoeficácia percebida pelos participantes observou-se que duas delas (Distribuição de discos e Tecnologia da informação) estão também classificadas como menos conhecidas por eles. De acordo com a Tabela 2, os dados indicaram uma tendência de grau de certeza na percepção de autoeficácia na maior parte das atividades ocupacionais em música entre Moderada e Muita.

Na Tabela 3 são apresentados os dados comparativos dos participantes sobre o total de atividades conhecidas, total de atividades em que se julga capaz de atuar com sucesso e o grau de certeza para atuar com sucesso na atividade ocupacional em música, conforme as características pessoais (sexo e idade) e profissional (se exerce atividade remunerada). Para a realização das comparações foi utilizado o teste de Mann-Whitney $(\mathrm{p}<0,05)$ e os resultados encontrados indicaram que não houve diferenças significativas entre os participantes do sexo masculino e feminino e nem para aqueles que exercem e que não exercem atividade remunerada na área.
Na Tabela 4 são apresentados os dados comparativos dos participantes sobre o total de atividades conhecidas, total de atividades que se julga capaz de atuar com sucesso e o grau de certeza para atuar com sucesso na atividade ocupacional em música, conforme a idade do participante, ano de ingresso na graduação e ano de finalização da graduação em música. Para a realização destas análises foi utilizado o teste de Kruskal-Wallis $(\mathrm{p}<0,05)$ que indicoudiferença significativa somente na comparação entre os anos de finalização do curso (entre 2000 e 2009) para a variável total de atividades conhecidas, sendo que os participantes que finalizaram o curso entre os anos de $2000 \mathrm{e}$ 2009 são o que mais conhecem atividades na área musical $(\mathrm{m}=41,68)$, seguido pelos participantes que finalizaram $\mathrm{o}$ curso anteriormente ao ano $2000(\mathrm{~m}=41,42)$.

A Tabela 5 apresenta análises de correlação entre as variáveis total de atividades conhecidas, total de atividades que se julga capaz de atuar com sucesso e o grau de certezapara atuar com sucesso na atividade ocupacional em música. Os resultados encontrados indicaram correlações positivas e significativas moderadas entre a totalidade de ocupações em que se percebe capaz e a totalidade de ocupações conhecidas $(\mathrm{r}=0,524)$. Assim, nota-se que à medida que aumenta o conhecimento sobre as ocupações da área de música aumenta também a totalidade de ocupações que se percebe capaz, o que denota a importância do conhecimento sobre as ocupações.

Semelhantemente, ocorreu a correlação positiva significativa entre a totalidade do grau de certeza e a totalidade de ocupações que se percebe capaz de atuar $(\mathrm{r}=$ $0,639)$. A tendência observada nas correlações indicou que quanto mais conhecimento sobre a atividade ocupacional em música maior é o grau da percepção de autoeficácia, como será discutido a seguir. 
Tabela 2

Análises descritivas das percepções de autoeficácia ocupacional em atividades musicais dos participantes

\begin{tabular}{|c|c|c|c|c|}
\hline \multirow[t]{2}{*}{ Ocupação } & \multicolumn{4}{|c|}{$\begin{array}{l}\text { Acha que seria capaz de atuar com suces- } \\
\text { so nesta atividade? (das que conhece) }\end{array}$} \\
\hline & $M$ & $d p$ & $\min$ & Max \\
\hline 30- Professor particular & 3,72 & 0,58 & 1 & 4 \\
\hline 33- Professor universitário & 3,62 & 0,72 & 2 & 4 \\
\hline 20- Instrumentista ou intérprete (tocando, cantando, gravando $\mathrm{p} /$ terceiros) & 3,56 & 0,72 & 1 & 4 \\
\hline 29- Música de câmara & 3,55 & 0,74 & 1 & 4 \\
\hline 28-Concertista (recitais solo) & 3,39 & 0,88 & 1 & 4 \\
\hline 35- Pesquisador & 3,38 & 0,85 & 1 & 4 \\
\hline 1-Banda/conjunto autoral & 3,23 & 0,85 & 1 & 4 \\
\hline 2- Banda/conjunto tributo ou cover & 3,17 & 0,79 & 2 & 4 \\
\hline 34- Professor em projetos sociais & 3,12 & 1,02 & 1 & 4 \\
\hline 32- Professor de escola particular regular & 3,08 & 0,92 & 1 & 4 \\
\hline 41- Replicação de mídia (vinil, CD, DVD) & 3,05 & 0,89 & 2 & 4 \\
\hline 12- Casa de show, teatro, boate, bar (música ao vivo) & 3,04 & 0,90 & 1 & 4 \\
\hline 27- Solista de orquestra & 3,03 & 1,02 & 1 & 4 \\
\hline 3- Banda/conjunto/orquestra de baile & 3,02 & 0,92 & 1 & 4 \\
\hline 31- Professor de escola pública regular & 2,96 & 1,01 & 1 & 4 \\
\hline 42- Organização de eventos (festivais, concursos, prêmios, shows) & 2,85 & 1,07 & 1 & 4 \\
\hline 25- DJ (rádio, show, festa, boate) & 2,83 & 1,03 & 1 & 4 \\
\hline 11- Direção artística (CD, DVD ou show) & 2,77 & 1,00 & 1 & 4 \\
\hline 45- Web (programação ou design para o setor) & 2,77 & 1,17 & 1 & 4 \\
\hline 4- Sonorização para eventos & 2,75 & 1,05 & 1 & 4 \\
\hline 26- Sinfônica (emprego público) & 2,73 & 1,19 & 1 & 4 \\
\hline 22- Arranjador & 2,72 & 1,08 & 1 & 4 \\
\hline 36- Estúdio de ensaios & 2,72 & 1,02 & 1 & 4 \\
\hline 37- Estúdio de gravação & 2,72 & 1,01 & 1 & 4 \\
\hline 21- Cantor independente (voz e violão, voz e teclado) & 2,68 & 1,08 & 1 & 4 \\
\hline 38- Estúdio móvel & 2,65 & 1,09 & 1 & 4 \\
\hline 39- Mixagem & 2,64 & 1,16 & 1 & 4 \\
\hline 16- Comércio de CD, DVD e afins & 2,63 & 1,01 & 1 & 4 \\
\hline 19- Composição (autor) & 2,63 & 1,15 & 1 & 4 \\
\hline 13- Produção fonográfica (gravadora) & 2,62 & 1,05 & 1 & 4 \\
\hline 8- Produção executiva (show ou CD,DVD) & 2,61 & 0,88 & 1 & 4 \\
\hline 6- Empresariamento artístico (management) & 2,60 & 0,93 & 1 & 4 \\
\hline 7- Agenciamento (booking) & 2,59 & 0,94 & 1 & 4 \\
\hline 5- Montagem de estrutura para eventos musicais & 2,58 & 1,02 & 1 & 4 \\
\hline 44- Design (capas e encartes de CD e DVD musicais, material gráfico) & 2,57 & 1,21 & 1 & 4 \\
\hline 9- Produção de tournê (tour management) & 2,54 & 0,96 & 1 & 4 \\
\hline 14- Edição musical (editora) & 2,54 & 1,16 & 1 & 4 \\
\hline 24- Trilha sonora (publicidade, jogos, teatro, cinema, moda) & 2,52 & 1,18 & 1 & 4 \\
\hline 40- Masterização & 2,48 & 1,12 & 1 & 4 \\
\hline
\end{tabular}


Tabela 2

Análises descritivas das percepções de autoeficácia ocupacional em atividades musicais dos participantes (Continuação)

\begin{tabular}{lcccc}
\hline \multirow{2}{*}{ Ocupação } & \multicolumn{3}{c}{$\begin{array}{c}\text { Acha que seria capaz de atuar com suces- } \\
\text { so nesta atividade? (das que conhece) }\end{array}$} \\
\cline { 2 - 5 } & $M$ & $d p$ & $\min$ & Max \\
\hline 47- Produtora de vídeo (clipes, documentários, DVDs) & 2,40 & 1,18 & 1 & 4 \\
46- Assessoria de imprensa (especializada em música) & 2,39 & 1,09 & 1 & 4 \\
17- Comércio de instrumentos, equipamentos e acessórios & 2,37 & 0,98 & 1 & 4 \\
43- Marketing cultural (elaboração e captação de projetos musicais) & 2,35 & 1,02 & 1 & 4 \\
18- Fabricação e reparo de instrumentos, equip, e acessórios & $\mathbf{2 , 3 3}$ & 0,97 & 1 & 4 \\
10- Técnica (som, luz, palco) & $\mathbf{2 , 3 2}$ & 1,25 & 1 & 4 \\
23- Maestro & $\mathbf{2 , 2 7}$ & 1,12 & 1 & 4 \\
48- Tecnologia da Informação (produtos para o setor) & $\mathbf{2 , 1 1}$ & 1,17 & 1 & 4 \\
15- Distribuição de discos (distribuidora) & $\mathbf{1 , 9 4}$ & 0,80 & 1 & 4 \\
\hline
\end{tabular}

Tabela 3

Análises de comparação entre características dos participantes para duas variáveis (sexo e exercício de atividade remunerada)

\begin{tabular}{llcc}
\hline & \multicolumn{2}{c}{ Sexo } & $p^{*}$ \\
\hline & Masculino & Feminino & \\
\hline Total de atividades Conhecidas & 38,87 & 38,83 & 0,972 \\
Total de atividades que se julga Capaz & 26,13 & 29,33 & 0,413 \\
Total Grau de Certeza & 1,73 & 1,58 & 0,476 \\
& & Atividade remunerada & \\
Total de atividades Conhecidas & Não & Sim & 0,599 \\
Total de atividades que se julga Capaz & 41,36 & 38,49 & 0,559 \\
Total Grau de Certeza & 28,36 & 26,06 & 0,271 \\
\hline
\end{tabular}

* Teste de Mann-Whitney

\section{Discussão}

Este estudo permitiu verificar o conhecimento dos participantes a respeito das possibilidades de atuação em atividades relacionadas à música. Observou-se que a maior parte deles conhece a maioria das atividades, ainda que uma pequena parte da amostra não tenha conhecimento sobre algumas das atividades. Nisso, merecem destaque as atividades de assessoria de imprensa, web, montagem de estrutura para eventos musicais, produção de tournê, replicação de mídia, distribuição de discos, estúdio móvel tecnologia da informação e agenciamento, das quais pelo menos $20 \%$ da amostra não as conheciam.

$\mathrm{Na}$ perspectiva de desenvolvimento de carreira o conhecimento sobre a atividade ocupacional é um fator relevante, isso devido ao fato de que conhecê-las pode ampliar a opções de atuação profissional amenizando a restrição de ocupações para a escolha e preparação necessária para atuação nela (Lent et al., 1987). Além disso, pelo motivo óbvio de que não é possível perceber-se capaz de realizar ações por atividades desconhecidas.

De modo geral, vale apontar que das 48 possíveis ocupações em atividades relacionadas à música proposta por Salazar (2010) havia ainda atividades desconhecidas para a amostra. Apesar de não serem poucas as atividades ocupacionais aqui investigadas, é relevante pensar sobre a variabilidade do mercado (Taubkin, 2011), ou seja, que o mercado de trabalho pode demandar mais profissionais músicos de uma determinada ocupação do que outra. Isso também pode ocorrer por conta da região geográfica em que os profissionais se encontram. Assim, algumas regiões geográficas podem estar mais saturadas do que outras conforme suas características de eventos sociais, culturais, turísticos e até econômicos. 
Tabela 4

Análises de comparação entre características dos participantes para três variáveis (idade, ano de ingresso e ano de finalização do curso)

\begin{tabular}{lcccc}
\hline & Idade $<30$ & Idade $30-39$ & Idade $>40$ & $p^{*}$ \\
\hline Total de atividades Conhecidas & 37,46 & 40,32 & 39,33 & 0,567 \\
Total de atividades que se julga Capaz & 25,43 & 27,58 & 26,13 & 0,790 \\
Total Grau de Certeza & 1,62 & 1,73 & 1,93 & 0,116 \\
& Ingressou & $2000-2009$ & $>=2010$ & \\
Total de atividades Conhecidas & $<2000$ & & & \\
Total de atividades que se julga Capaz & 39,17 & 40,95 & 34,81 & 0,054 \\
Total Grau de Certeza & 26,04 & 26,84 & 26,05 & 0,947 \\
& 1,92 & 1,68 & 1,58 & 0,085 \\
& Finalizou & $2000-2009$ anos & $>=2010$ ano & \\
Total de atividades Conhecidas & $<$ ano 2000 & & & \\
Total de atividades que se julga Capaz & 41,42 & 41,68 & 36,56 & 0,009 \\
Total Grau de Certeza & 27,00 & 26,19 & 26,75 & 0,936 \\
\hline
\end{tabular}

* Teste de Kruskal-Wallis

Tabela 5

Correlações entre escores das subescalas de autoeficácia ocupacional em atividades musicais

\begin{tabular}{lcc}
\hline & Total Conhece & Total Capaz \\
\hline Total Capaz* & $r=\underline{0,524}$ & \\
& $p=<, 0001$ & \\
Total Certeza & $\underline{0,3430,639}$ & \\
& 0,0015 & $<, 0001$ \\
\hline
\end{tabular}

* r=coeficiente de correlação de Spearman; $\mathrm{P}=$ Valor-P; $\mathrm{n}=$ número de sujeitos $(\mathrm{n}=83)$.

Vale lembrar que parte da amostra foi composta por estudantes de graduação em música. Assim, vale questionar em que medida os cursos de graduação tem proporcionado aos estudantes condições favorecedoras para se pensar na construção de seu projeto de vida com foco na carreira? A literatura tem apontado que iniciativas como participação em atividades acadêmicas de formação, conhecimento sobre a situação de mercado de trabalho, decisão de carreira, percepção de oportunidades profissionais tem contribuindo para a construção de carreira na perspectiva de percepções de autoeficácia (Teixeira \& Gomes, 2005). Isso vale também para o caso da formação em Música, assim quais têm sido as iniciativas que contribuam para sua formação?

Das percepções de autoeficácia ocupacional em atividades musicais foi constatada uma tendência de respostas sobre o grau de certeza com escores entre 2 e 3 numa escala que variou de 1 a 4 , ainda vale investigar se as percepções de autoeficácia estão alinhadas com as habilidades dos participantes. Importa dizer que as percepções de autoeficácia influenciam na motivação, na seleção, na cognição e estados afetivos das pessoas e diante da possibilidade de construção da carreira tais aspectos são merecedores de atenção (Bandura, 1997; Pajares \& Olaz, 2008). Além de não serem isoladas, enquanto processos cognitivos podem impactar na formação dos interesses, nas escolhas de metas e no próprio desempenho seja ele acadêmico ou profissional. Assim, aspectos importantes encontrados em pesquisas relacionadas às percepções de autoeficácia e carreira como o fator de predição comportamental para a realização acadêmica, persistência ao longo do curso, interesses ocupacionais (Lent et al., 1987; 2003b), planejamento de carreira (Ourique, 2010), comportamento exploratório de carreira (Bardagi \& Boff, 2010) e maior amplitude de opções de carreiras (Lent et al., 1987) podem contribuir para a elaboração de intervenções.

Os dados indicaram que a percepção de autoeficácia para atividades ocupacionais com médias menos elevadas também eram as menos conhecidas pelos participantes. $\mathrm{O}$ que retoma a proposta de que o conhecimento sobre a atividade ocupacional pode exercer um papel fundamental para o planejamento de carreira. Esta condição também foi confirmada ao identificar as análises de correlações positivas e significativas entre as variáveis estudadas, sendo que à medida que se tem conhecimento sobre a atividade mais se percebe capaz; à medida que se conhece a atividade ocupacional, maior o grau de certeza sobre perceber-se capaz de realizá-la. Tal dado encontrado 
remete a pensar sobre a formação do músico e o papel da organização dos currículos da graduação em música no Brasil. Assim, em termos de escolha profissional do músico indaga-se em que momento ela ocorre para que possa planejar sua carreira?

Nas análises comparativas das variáveis entre os grupos não foram identificadas diferenças significativas entre os sexos, diferentemente dos apontados da literatura para um conjunto de diferentes ocupações (Betz \& Hackett, 1981; Coimbra \& Fontaine; 2010). Possivelmente este resultado seja característico das ocupações relacionadas às atividades musicais. De acordo com a literatura, as diferenças entre os sexos para interesses e escolhas profissionais sempre marcaram a construção de carreira, embora não sejam determinantes e estejam relacionadas à cultura de um determinado local. Para os demais grupos que foram comparados pelas características profissional (exercício de trabalho remunerado), pessoal (idade) e de formação (ano de ingresso no curso de graduação) não foram identificadas diferenças significativas nas variáveis investigadas. Embora sejam condições importantes que podem impactar tanto no conhecimento das atividades ocupacionais quanto nas percepções de autoeficácia, o grupo investigado não demonstrou diferenças. Apenas para o grupo que finalizou o curso entre os anos 2000 e 2009 foi identificada diferença significativa para a variável total de atividades conhecidas.

Das contribuições de pesquisas que investigaram as crenças de autoeficácia pautadas na TSCC destacam-se as recomendações para as intervenções (Lent et al., 1991; $2003 \mathrm{~b}$; 2010) e incentivos que os estudantes precisam com o intuito de modificar suas percepções, em especial para aqueles que subestimam suas metas educacionais e vocacionais (Lent et al., 1984). Além disso, intervenções que ajudem os estudantes no planejamento de carreira para que possam promover a percepção de crenças de autoeficácia realistas e otimistas, expectativas de resultados baseados em informações precisas, identificação de interesses que não sejam prematuramente definidos por limitações experienciais ou vieses cognitivos e objetivos claros/próximos com o intuito de que os estudantes possam mobilizar apoio e negociar barreiras à sua preferência ocupacional (Lent, Lopes, \& Bieschke,1991; Lent et al., 2010), em especial a carreira musical.

\section{Considerações Finais}

De modo geral, os objetivos desta investigação foram alcançados, nos quais verificaram-se: 1) as ocupações musicais mais conhecidas pelos participantes; 2) as percepções dos participantes sobre as crenças de autoeficácia ocupacional em atividades musicais, comparando os grupos quanto ao sexo, idade, ano de ingresso e se exerce atividade remunerada; e 3) correlação entre as variáveis de totalidade de ocupações conhecidas, a totalidade de ocupações que se percebe capaz e o grau de certeza que se percebe capaz para atuar com sucesso na ocupação. Destaca-se que nem todas as ocupações são conhecidas pelos participantes e nem todos se perceberam capazes para atuar com sucesso nelas, e ainda variáveis pessoais e sociais não se diferenciaram quanto ao conhecimento e percepção de eficácia, exceto o ano de finalização do curso. Espera-se que tais achados possam contribuir para a formação do músico bem como para o desenvolvimento de carreira.

Pode-se citar como limitação deste trabalho o número restrito de participantes. Assim, sugere-se a ampliação de participantes em pesquisas futuras e em especial com estudantes da área em música, de modo que se identifiquem aspectos de sua formação e perspectivas de carreira. Para melhor fomentar a temática investigada, sugeremse pesquisas qualitativas. Espera-se também que haja um mapeamento refinado sobre as atividades ocupacionais em música, visto a expansão do mundo do trabalho, e que esses dados possam apoiar práticas de formação deste profissional. A respeito da proposta teórica que norteou esta investigação é necessário que os demais construtos sejam incluídos em pesquisas futuras contribuindo assim para uma melhor compreensão do fenômeno, bem como intervenções na área que colaborem para o desenvolvimento de carreira destes profissionais.

\section{Referências}

Bandura, A. (1997). Self-efficacy: The exercise of control. New York: W. H. Freeman.

Bandura, A. (2008). O sistema do self no determinismo recíproco. In Bandura, A., Azzi, R. G., \& Polydoro, S.. Teoria Social Cognitiva: Conceitos Básicos (p. 176-187). Porto Alegre: Artmed.

Bardagi, M. P., \& Boff, R. M. (2010). Autoconceito, auto-eficácia profissional e comportamento exploratório em universitários concluintes. Avaliação, 15(1), 41-56. doi:10.1590/S1414-40772010000100003.

Betz, N. E., \& Hackett, G. (1981). The relationship of career-related self-efficacy expectations to perceived career options in college women and men. Journal of Counseling Psychology, 28(5), 399-410. Recuperado em 01 de agosto de 2017, em psycnet.apa.org/record/1982-02194-001 
Betz, N. E. (2004). Contributions of self-efficacy Theory to career counseling: a personal perspective. The Career Development Quarterly, 52, 340-353. doi:10.1002/j.2161-0045.2004.tb00950.x

Brazil, M. A. (2017). Leitura musical para iniciantes em aulas coletivas de violão: uma visão através da Teoria da Autoeficácia. Tese de Doutorado não-publicada, Universidade Federal da Bahia, Bahia.

Cereser, C. M., Oliveira, M. A. W., \& Hentschke, L. (2016).Um estudo sobre crenças de autoeficácia de professores de música para usar as TIC no ensino público brasileiro. Resumos na Programação Geral do SIMCAM, (p. 21). Porto Alegre: UFRGS.

Coimbra, S. M. G. (2000). Estudo diferencial da autoeficácia em alunos do $9^{\circ}$ ano de escolaridade. 295 f. Dissertação de Mestrado. Universidade do Porto. Faculdade de Psicologia e de Ciências da Educação.

Coimbra, S. M., \& Fontaine, A. M. (2010). Será que sou capaz? Estudo diferencial de autoeficácia com alunos do nono ano. Revista Brasileira de Orientação Profissional, 11(1), 5-22.

Dantas, M. A. (2015). Autoeficácia ocupacional e de decisão de carreira: análise de uma intervenção em estudantes do ensino médio público. Tese de Doutorado não publicada, Universidade Estadual de Campinas, Campinas.

Dantas, M. A., \& Azzi, R. G. (2015). Autoeficácia ocupacional e interesses percebidos por estudantes do Ensino Médio público. Revista Psicologia: Ensino \& Formação, 6(1), 52-71.

Dantas, M. A., Azzi, R. G., \& Noronha, A.P.P. (no prelo) Evidências de validade da Escala de Autoeficácia Ocupacional de Formação e Interesses.

Glazer, S. L., \& Bardagi, M. P. (2011). Habilidades sociais, autoeficácia e decisão de carreira em universitários em final de curso. Boletim-Academia Paulista de Psicologia, 80(3), 148-165.

Kruger, F. (2016). O perfil de formação musical do professor que trabalha com música no ensino médio e a sua relação com as crenças de autoeficácia. Resumos na Programação Geral do SIMCAM, p. 19. Porto Alegre: UFRGS.

Lent, R. W., Brown, S. D., \& Hackett, G. (1994). Toward a unifying Social Cognitive Theory of career and academic interest, choice, and performance. Monografh. Journal of Vocational Behaviors, 45, 79-122. doi:10.1006/jvbe.1994.1027

Lent, R. W., Brown, S. D., \& Larkin, K.C. (1984). Relation of self-efficacy expectations to Academic Achievement and Persistence. Journal of Counseling Psychology, 31(3), 356-362. doi:10.1037/0022-0167.31.3.356

Lent, R. W., Brown, S. D., \& Larkin, K. C. (1987). Comparison of Three Theoretically derived variables in predicting Career and Acadmeic Behavior: self-efficacy, interest congruence, and consequence thinking. Journal of Counseling Psychology, 34(3), 293-298. doi:10.1037/00220167.34.3.293

Lent, R. W., Brown, S. D., Nota, L., \& Soresi, S. (2003a). Testing social cognitive interest and choice hypotheses across Holland types in Italian high school students. Journal of Vocational Behavior, 62(1), 101-118. doi:10.1016/ S0001-8791(02)00057-X

Lent, R. W., Brown, S. D., Schimidt, J., Brenner, H. L., Lions, H., \& Treistman, D. (2003b). Relation of contextual supports and barriers to choice behavior in engineering majors: Test of alternative Social Cognitive Models. Journal of Counseling Psychology, 50(4), 458-465. doi:10.1037/0022-0167.50.4.458

Lent, R. W., Lopes, F. G., \& Bieschke, K. L. (1991). Mathematics self-efficacy: sources and relation to science-based career choice. Journal of counseling Psychology, 38(4), 424-430. doi:10.1037/0022-0167.38.4.424

Lent, R.W., Paixão, M. P., Silva, J. T., \& Leitão, L. M. (2010). Predicting occupational interest and choice aspirations in Portuguese high school students: A test of social cognitive career theory. Journal of Vocational Behavior, 76(2), 244-251. doi:10.1016/j.jvb.2009.10.001

Masotti, D. R., \& Noronha A. P. P. (2015). Estudo correlacional entre interesses profissionais e autoeficácia com tecnólogos. Interação em Psicologia, 19(1), 107-117. doi:10.5380/psi.v19i1.28920

Nunes, C. H. S. S., \& Primi, R. (2010). Aspectos técnicos e conceituais da ficha de avaliação dos testes psicológicos. In: Santos, A. A. A., Anache, A. A., Villemor-Amaral, A. E., Werlang, B. S. G., Reppold, C. T., Nunes, C. H. S. S., Corrêa, F. B., Tavares, M., Ferreira, M. C., Nascimento, R., Primi, R. (Orgs.). Avaliação Psicológica: Diretrizes na Regulamentação da Profissão. (v. 1, pp. 101-127. 1ed. Brasília: Conselho Federal de Psicologia. 
Ourique, L. R.. (2010). Auto-eficácia e Personalidade no Planejamento de Carreira de Universitários. 84p. Mestrado. Universidade Federal do Rio Grande do Sul - Psicologia.

Pajares, F., \& Olaz, F. (2008). Teoria Social Cognitiva e autoeficácia: uma visão geral. In: Bandura, A.; Azzi, R.G.; Polydoro, S. Teoria Social Cognitiva: Conceitos Básicos. 1ed., p. 176). Porto Alegre: Artmed.

Ropke, C. B. (2016). Crenças de autoeficácia dos professores de música que atuam na educação infantil: uma pesquisa em andamento. Resumos na Programação Geral do SIMCAM, (p. 19). Porto Alegre: UFRGS.

Salazar, L.(2010). Música Ltda. O negócio da música para empreendedores. Recife, SEBRAE.

Teixeira, M. A. P., \& Gomes, W.B. (2005). Decisão de Carreira entre Estudantes em fim de curso Universitário. Psicologia: Teoria e Pesquisa, 21(3), 327-334.

Tourinho, C., Azzi, R. G., \& Dantas, M. A. (2016). Crenças de autoeficácia ocupacional de estudantes e recém-egressos de cursos de bacharelado em violão. Percepta, 3(2), 49-68. doi:10.34018/2318-891X.3(2)49-68

Tourinho, C., \& Azzi, R. (2016). Crenças de autoeficácia de violonistas para atuação profissional.Resumos na Programação Geral do SIMCAM, (p. 27). Porto Alegre: UFRGS.

Werner, A. S. (2016). Professores dos anos iniciais e suas crenças de autoeficácia. Resumos na Programação Geral do SIMCAM, (p. 20). Porto Alegre: UFRGS.

Taubkin, B. (2011). Viver de Música. Diálogos com Artistas Brasileiros. São Paulo, Bei Comunicações.

Recebido: $25 / 09 / 17$

Aceito: $19 / 02 / 19$

Sobre as autoras:

Marilda Aparecida Dantas é Psicóloga, Mestre em Avaliação Psicológica pela Universidade São Francisco, Doutora em Educação pelo Programa de Pós-Graduação em Educação da Faculdade de Educação da UNICAMP e atua como psicóloga no Serviço de Apoio ao Estudante da UNICAMP.

Roberta Gurgel Azzi é Psicóloga, Mestre em Psicologia Experimental (USP) eDoutora em Educação (UNICAMP). Professora Livre-docente, aposentada, da Faculdade de Educação da UNICAMP. Diretora da TSC - Centro de Estudos e Pesquisas.

Cristina Tourinho é Graduada como Professora de Violão pela Universidade Católica do Salvador, Instrumento pela Universidade Federal da Bahia, mestrado e doutorado em Música pela Universidade Federal da Bahia e pós-doutorado na Universidade Estadual de Campinas. É Professor Associado IV da UFBA.. 